\title{
Direct Organogenesis from Cotyledons in Cultivars of Citrus clementina Hort. Ex Tan
}

\author{
Giovanna Lombardo ${ }^{1}$, Roberta Alessandro ${ }^{2}$, Anna Scialabba ${ }^{1}$, Mariangela Sciandra $^{3}$, \\ Fabio De Pasquale ${ }^{4}$
}

\begin{abstract}
${ }^{1}$ Department of Environmental Biology and Biodiversity, University of Palermo, Palermo, Italy; ${ }^{2}$ Department of Agro and Environmental Systems (S.Ag.A.), University of Palermo, Palermo, Italy; ${ }^{3}$ Department of Mathematical and Statistical Sciences "Silvio Vianelli", University of Palermo, Palermo, Italy; ${ }^{4}$ Institute of Plant Genetics, National Council of Research, Research Division Palermo, Palermo, Italy.
\end{abstract}

Email: giolombardo@unipa.it

Received March 1 $1^{\text {st }}, 2011$; revised April 23 ${ }^{\text {rd }}, 2011$; accepted April 30 $0^{\text {th }}, 2011$.

\begin{abstract}
An efficient protocol to induce shoot buds regeneration in Citrus clementina cultivars ("Monreal", "SRA 63" and "SRA 64") by direct organogenesis has been developed using cotyledons as explants. Cotyledons transversely cut in three segments and entire ones were cultured on Murashige and Skoog (1962) solidified medium containing vitamins, 500 $\mathrm{mg} \cdot \Gamma^{1}$ malt extract, $50 \mathrm{~g} \cdot l^{-1}$ sucrose and supplemented with three different concentrations of BAP $(8.8,13.2$ and 17.6 $\mu M)$. In all three cultivars the entire cotyledons showed more shoot morphogenic potential than transversely cut ones and after 60 incubation days the optimum BAP concentration was $17.6 \mu M$ in "Monreal" $(50 \% \pm 2.89 \%$ of frequency regeneration ) and $13.2 \mu M$ in "SRA 63" (33.33\% $\pm 3.33 \%)$ and "SRA 64" $(25.93 \% \pm 1.85 \%)$. In absence of BAP No morphogenesis occurred, demonstrating the absolute requirement of this hormone for shoots induction. The young shoots showed a regular growth in the culture tubes containing the basal medium without hormones, and the rooted plantlets survived after acclimatization. This protocol may find application in Citrus genetic improvement programs.
\end{abstract}

Keywords: Citrus clementina, Cotyledons, Direct Organogenesis, Plant Regeneration, Tissue Culture

\section{Introduction}

Citrus clementina Hort. ex Tanaka is a very important crop because of its excellent organoleptic and easypeeling qualities. In C. clementina, as in Citrus spp., bud mutations arise spontaneously [1-4] and growers select them to improve horticultural traits of economically interesting species; there is also a high degree of interspecific sexual compatibility, so clementine is highly used in genetic improvement programs as mother plant to obtain new genotypes through hybridization by controlled inbreeding.

In vitro technique is a useful method to obtain trueto-type regenerated plants $[5,6]$ as well as to induce somatic mutations [7] affecting characters of agronomic interest in order to develop new and improved genotype lines. There are several studies on plant regeneration by organogenesis and embryogenesis from different types of explants in Citrus genus [8-13], but very little information is available about procedures for achieving regeneration from clementine mandarin: embryos were induced from calli of ovular tissue [14], aberrant plants were obtained by direct and indirect somatic embryogenesis from the nucellus of eight cultivars [7], and gynogenesis [15] and androgenesis [16-18] were studied in different cultivars.

Cotyledons have high potential of regeneration $[19,20]$ and represent a good source of tissue cultures. Organogenesis from cotyledons was successfully obtained in Pongamia pinnata (L.) [21], Glicine $\max$ (L.) Merril [22], Dalbergia sissoo Roxb. [23], Capsicum annum L. [24] and Citrullus lanatus (Thunb.) Matsum. \& Nakai [25]. Beyond, in the last decade cotyledons and cotyledonary nodal regions were used as target tissues for transformation mediated by Agrobacterium [20].

The aim of this work was to induce in vitro plant regeneration in Citrus clementina to be used in Citrus genetic improvement programs. Three cultivars were investigated in the experiments and cotyledons were used as explants.

\section{Materials and Methods}

Ripe fruits of C. clementina "Monreal", "SRA 63" and 
"SRA 64" of the germplasm collection belonging to the Istituto di Genetica Vegetale (sezione di Palermo), National Research Council (CNR) of Italy, were sampled at the beginning of December. The seeds, derived from open pollination, were drawn aseptically from the fruits into a laminar air flow and deprived of two teguments and of the embryo axis with a scalpel and forceps. Entire cotyledons (EC) and transversely cut cotyledons (CC) were used as explants. EC has one cut surface only, while $\mathrm{CC}$ were obtained cutting the cotyledon into three segments: the segment close to the embryo axis, identified as proximal (CCp), and the one next to it, called middle $(\mathrm{CCm})$, have two cut sides each, while the farthest segment is the distal (CCd) and has one cut side. EC and CC were cultured on Murashige and Skoog [26] solidified medium containing vitamins, $500 \mathrm{mg} \cdot \mathrm{l}^{-1}$ malt extract and $50 \mathrm{~g} \cdot \mathrm{l}^{-1}$ sucrose as basal medium. Three different concentrations of 6-benzylaminopurine (BAP) were tested in the basal medium: $8.8 \mu \mathrm{M}, 13.2 \mu \mathrm{M}$ and $17.6 \mu \mathrm{M}$. The $\mathrm{pH}$ of the medium was adjusted to 5.7 with $1 \mathrm{~N} \mathrm{KOH}$ and the medium was autoclaved at $103 \mathrm{kPa}$ $\left(121^{\circ} \mathrm{C}\right)$ for $20 \mathrm{~min}$. Shoots about $5 \mathrm{~mm}$ long were isolated from cotyledons and transferred into culture tubes containing a hormone-free medium. Preliminary experiments were performed in the same culture conditions using seeds of fruits collected in the middle of November. All explants were incubated in a climate chamber at $26^{\circ} \mathrm{C}$ $\pm 1^{\circ} \mathrm{C}$ under 16-h photoperiod. Rooted plants were transferred into Jiffy $7^{\circledR}$ peat pellets to the green house and, when the radical apparatus was formed, they were potted and slowly submitted to acclimatization. Experiments were performed with 10 seeds per treatment and repeated thrice. The regeneration frequency (RF) (number of explants producing buds or shoots per total number of explants cultured multiplied 100), the number of buds/shoots per explant and shoot elongation were measured at 30, 60 and 90 days of culture.

\section{Statistical Analysis}

The statistical analysis was carried out at first through a descriptive analysis in which the data were presented as a mean value with its relative standard error by using Microsoft Office Excel 2003.

Following, the distributions of regeneration frequency, number of buds/shoots per explant and shoot elongation have been studied in order to properly specify a statistical model able to relate these dependent variables to the three explanatory variables BAP concentration, explant type and genotype.

BAP concentration was considered as a continuous variable while explant type and genotype were considered as factor variables with respectively four $(\mathrm{EC}, \mathrm{CCd}$, $\mathrm{CCm}, \mathrm{CCp}$ ) and three ("Monreal", "SRA 63", "SRA 64") levels.

The relationship between dependent and explanatory variables was modelled by using three different Generalized Linear Models (GLM) [27] according to the distribution of the response variables considered. In particular, in the regeneration frequency case, being a dichotomous variable $(0=$ No regeneration, $1=$ regeneration $)$, a binomial GLM was fitted; number of buds/shoots per explant was modelled through a Poisson GLM as it is a counting variable and finally shoot elongation was modelled by a Gamma GLM as its distribution showed a marked positive skewness. The best three GLMs resulted from a model selection procedure based on the Akaike Information Criterion (AIC) [28].

The statistical modelling has been carried out using $R$ (R Development Core Team 2005) [29], a public domain statistical environment freely downloadable from the URL www.R-project.org.

\section{Results and Discussion}

Shoots began to emerge directly from the explants after three weeks of incubation and no callus around the emerging shoots was observed under the stereo microscope (Figure 1(a)). Callusing alone occurred very rarely and indirect organogenesis was never observed. The shoots in formation appeared as clusters of green protuberances that successively differentiated into buds (Figure 1(b)). They arose more frequently from the cut sides (Figure 1(c)) in both EC and CC and rarely directly from the intact cotyledon surface. Regeneration in all genotypes only occurred in the presence of BAP (Figure 2), that has a significant effect $(\mathrm{p} \leq 0.001)$ on the regeneration probability (Table 1(A)), while neither swelling nor morphogenic responses were noted when using the hormone-free basal medium. All BAP concentrations induced morphogenesis in "Monreal" and "SRA 64", whereas in "SRA 63" only the lowest level of BAP ( 8.8 $\mu \mathrm{M})$ in $\mathrm{EC}$ and the highest concentration $(17.6 \mu \mathrm{M})$ in the proximal segments were not inductive after 90 culture days (Figure 2). The young differentiated shoots transferred to the basal medium without growth regulators rooted easily and put new leaves, showing a regular growth (Figure 1(d)). The plantlets survived to the transfer to Jiffy $7^{\circledR}$ peat pellets into the green house and were acclimatized successfully after having been potted (Figure 1(e)). The entire process, from shoot emergence to plant acclimatation, was accomplished approximately in four-six months.

"Monreal" (Figure 2(a)) was the most reactive and fastest cultivar in terms of RF but only for EC explants: after 30 incubation days the RF was $33.33 \pm 2.22$ and $41.48 \pm 1.48$ respectively in $13.2 \mu \mathrm{M}$ and $17.6 \mu \mathrm{M}$ of BAP and an increasing trend to raise hormone concentration 
was observed. The best regenerative potential was obtained by $\mathrm{EC}$ in $17.6 \mu \mathrm{M}(50 \% \pm 2.89 \% \mathrm{RF})$ after 60 incubation days. Proximal, middle and distal segments morphogenically responded in an unremarkably different way to BAP treatment.

In "SRA 63" (Figure 2(b)) the best BAP concentration for all explants was $13.2 \mu \mathrm{M}$ and the most regenerative were EC and the middle segments (in both $33.33 \% \pm$ $3.33 \% \mathrm{RF}$ ); these regeneration percentages were reached after 60 incubation days and held steady in both explants after 90 days. A slightly lower regenerative response was obtained in the distal segments in $13.2 \mu \mathrm{M}$ of BAP $(26.67 \% \pm 3.33 \%)$, while $17.6 \mu \mathrm{M}$ concentration induced poor organogenesis, ranging from $6.67 \% \pm 1.67 \%$ (distal segment) to $13.33 \pm 3.33$ (EC and middle segment) after 90 days of incubation.

In "SRA 64" (Figure 2(c)) the best regeneration occurred in EC in BAP $13.2 \mu \mathrm{M}(30.04 \% \pm 3.92 \% \mathrm{RF})$ after 90 incubation days. Regarding $\mathrm{CC}$, the best morphogenetic response was obtained in the distal segments in BAP $13.2 \mu \mathrm{M}(21.85 \pm 0.37 \mathrm{RF})$ and in the middle segments in both 8.8 and $13.2 \mu \mathrm{M}(18.52 \pm 3.70)$ concentrations after 90 incubation days. Regeneration was very low in proximal segments, ranging from $3.70 \pm 1.85$
(BAP $17.6 \mu \mathrm{M}$ ) to $7.04 \pm 1.48$ (BAP $13.2 \mu \mathrm{M})$.

The probability of regeneration (Table $\mathbf{1}(\mathbf{A})$ ) is different in the three genotypes: "SRA 64" (p_0.001) had a probability of regeneration lower than the "Monreal", while the probability of regeneration for the "SRA 63" (p_0.05) resulted marginally different from the "Monreal". Beyond, the probability of regeneration for the entire cotyledon was significantly higher than the other three explant types (Table 1(A)).

The number of buds/shoots differentiated per explant after 60 days of incubation (Table 2) ranged from 1 to $4.28 \pm 1.37$ in all cultivars. Only the explant types resulted significant (Table 1(B)) so the other two variables (BAP concentration and genotype) were eliminated from the model in the Table 1(B). Significative differences in the number of buds/shoots per explant variable were achieved between the entire cotyledon and the distal $(\mathrm{p} \leq$ $0.001)$ and medium $(p \leq 0.05)$ segments; on the contrary entire cotyledon and proximal segment are not significatively different between them and they were the explants with the highest number of buds/shoots differentiated per explant.

The shoots generated from EC explants (Table 2) was always significatively much longer $(\mathrm{p} \leq 0.001)$ than the

Table 1. Akaike Information Criterion statistical procedure on the regeneration frequency variable (A), the number of buds/shoots per explant variable (B) and the shoot elongation variable (C) in Citrus clementina cultivars, estimated respectively from a GLM-binomial, GLM-Poisson and GLMGamma (link Identity). Intercept 1 represents "Monreal", hormone-free medium and entire cotyledon; intercept 2 and 3 represent entire cotyledon; 6-benzylaminopurine (BAP); transversely cut cotyledons distal $(\mathrm{CCd})$, middle $(\mathrm{CCm})$ and proximal $(\mathrm{CCp})$ segments. Significance codes: ‘***’ $\mathbf{p} \leq 0.001 ;{ }^{6 * *}, \mathbf{p} \leq$ $0.01 ; “ * ” p \leq 0.05 ; "$ ". $p \leq 0.1$; “" $p \leq 1$. Standard error (SE).

\begin{tabular}{|c|c|c|c|c|c|c|}
\hline & & & Estimate & SE & z- & p-value \\
\hline \multirow{7}{*}{ A } & \multirow{7}{*}{$\begin{array}{c}\text { Regeneration } \\
\text { Frequency variable }\end{array}$} & Intercept 1 & -2.366 & 0.296 & -7.988 & $1.37 \mathrm{e}-15$ \\
\hline & & BAP & 0.113 & 0.018 & 6.129 & $8.82 \mathrm{e}-10$ \\
\hline & & “SRA 63” & -0.453 & 0.247 & -1.830 & 0.067 \\
\hline & & “SRA 64" & -0.960 & 0.228 & -4.214 & $2.50 \mathrm{e}-05$ \\
\hline & & $\mathrm{CCd}$ & -0.728 & 0.257 & -2.827 & $0.004 * *$ \\
\hline & & $\mathrm{CCm}$ & -0.574 & 0.249 & -2.304 & $0.021 *$ \\
\hline & & $\mathrm{CCp}$ & -1.047 & 0.278 & -3.763 & $0.0001 * * *$ \\
\hline \multirow{4}{*}{ B } & \multirow{4}{*}{$\begin{array}{c}\text { Number of } \\
\text { buds/shoots per } \\
\text { explant variable }\end{array}$} & Intercept 2 & 1.247 & 0.074 & 16.780 & $<2 \mathrm{e}-16 * * *$ \\
\hline & & $\mathrm{CCd}$ & -0.505 & 0.146 & -3.454 & $0.0005^{* * *}$ \\
\hline & & $\mathrm{CCm}$ & -0.324 & 0.132 & -2.451 & $0.014^{*}$ \\
\hline & & $\mathrm{CCp}$ & 0.005 & 0.136 & 0.040 & 0.967 \\
\hline \multirow{4}{*}{$\mathrm{C}$} & \multirow{4}{*}{$\begin{array}{c}\text { Shoot elongation } \\
\text { variable }\end{array}$} & Intercept 3 & 5.117 & 0.560 & 9.131 & $9.68 \mathrm{e}-16$ \\
\hline & & $\mathrm{CCd}$ & -2.394 & 0.684 & -3.498 & $0.0006^{* * *}$ \\
\hline & & $\mathrm{CCm}$ & -3.1549 & 0.621 & -5.082 & $1.24 \mathrm{e}-06^{* * *}$ \\
\hline & & $\mathrm{CCp}$ & -2.612 & 0.701 & -3.725 & $0.0002 * * *$ \\
\hline
\end{tabular}




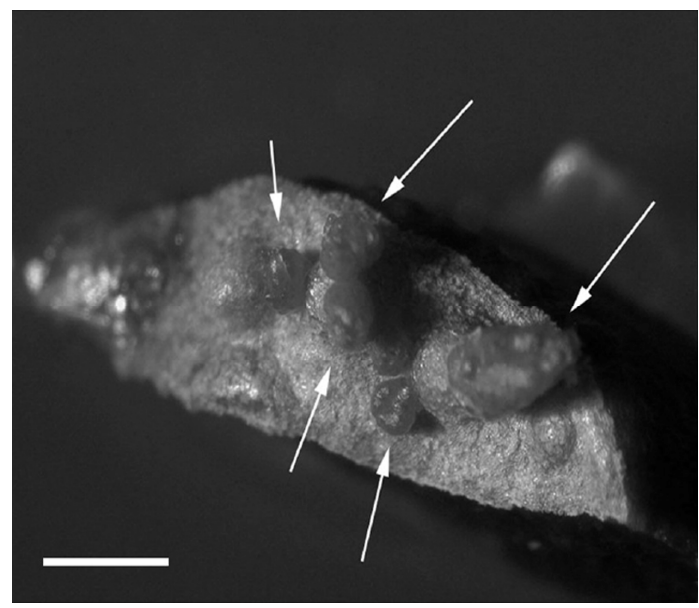

(a)

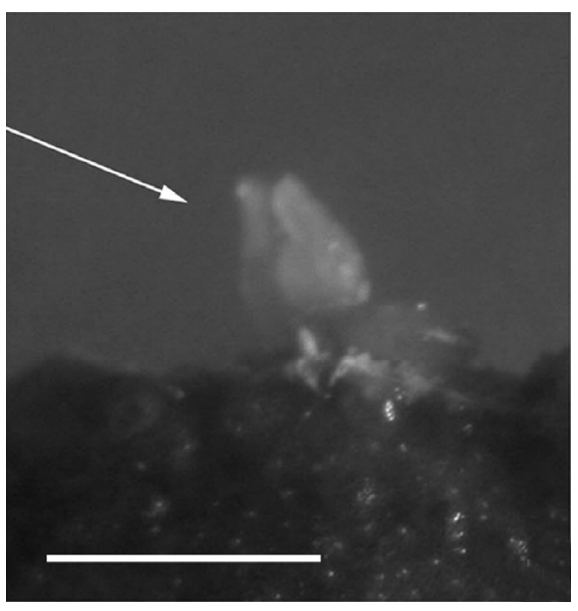

(b)

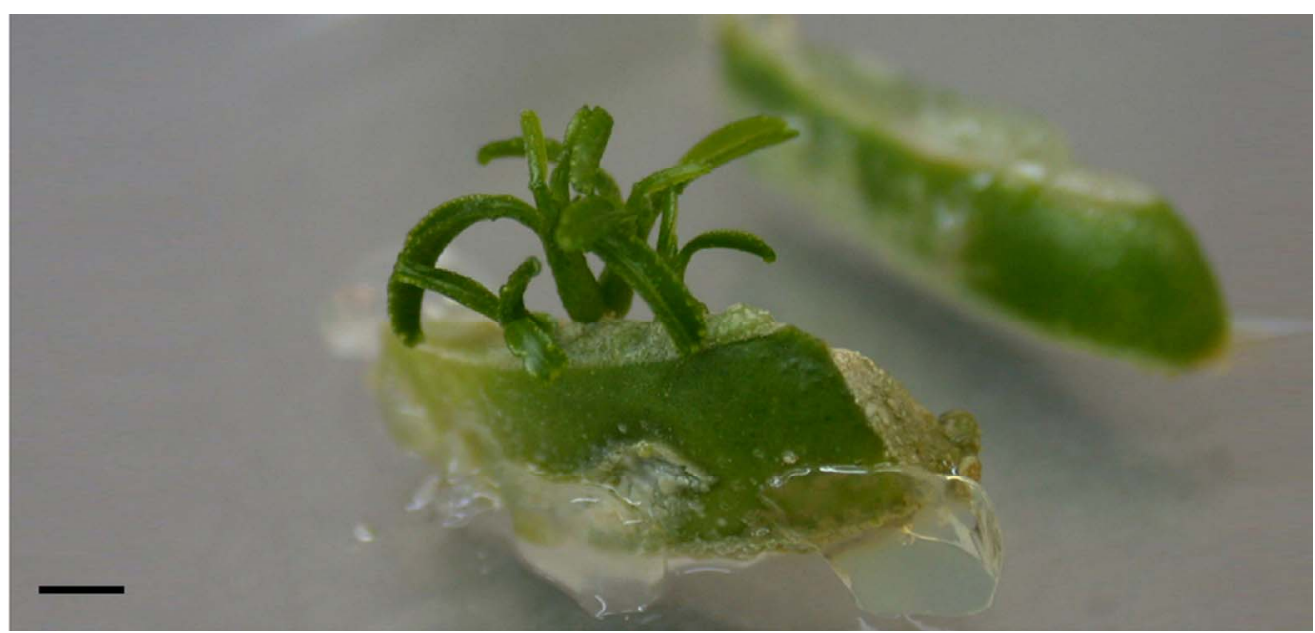

(c)

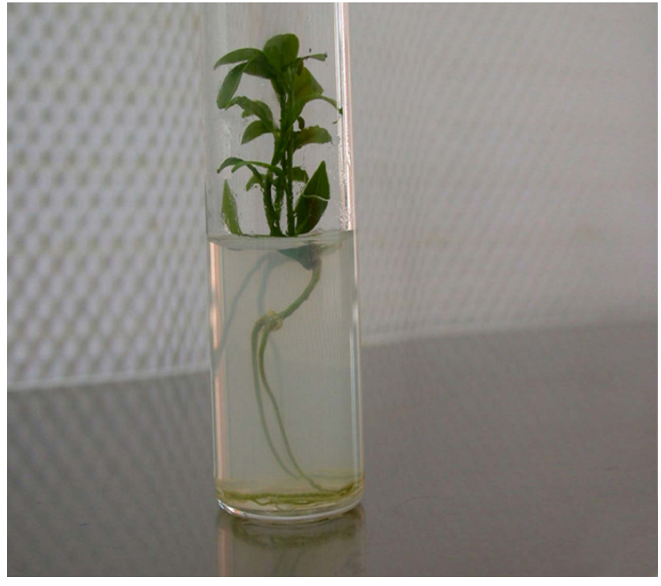

(d)

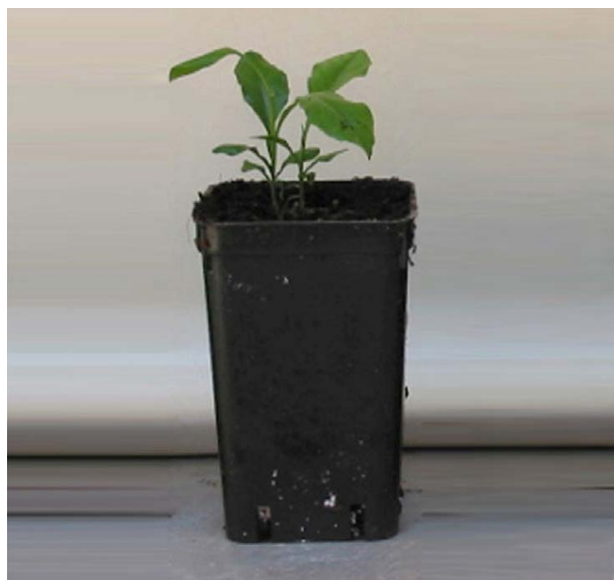

(e)

Figure 1. Different development stages in the plantlet formation via direct organogenesis from cotyledons in Citrus clementina "Monreal"; the same pattern occurred in "SRA 63" and "SRA 64". (a) Regeneration appeared with clusters of green swelling and protuberances (arrows); (b) Differentiation of bud (arrow); (c) Shoots arising from the wounded side; (d) Shoot transferred in the hormone-free basal medium showing a regular growth; (e) Potted plant established in vivo conditions. Bars = 1 mm. 


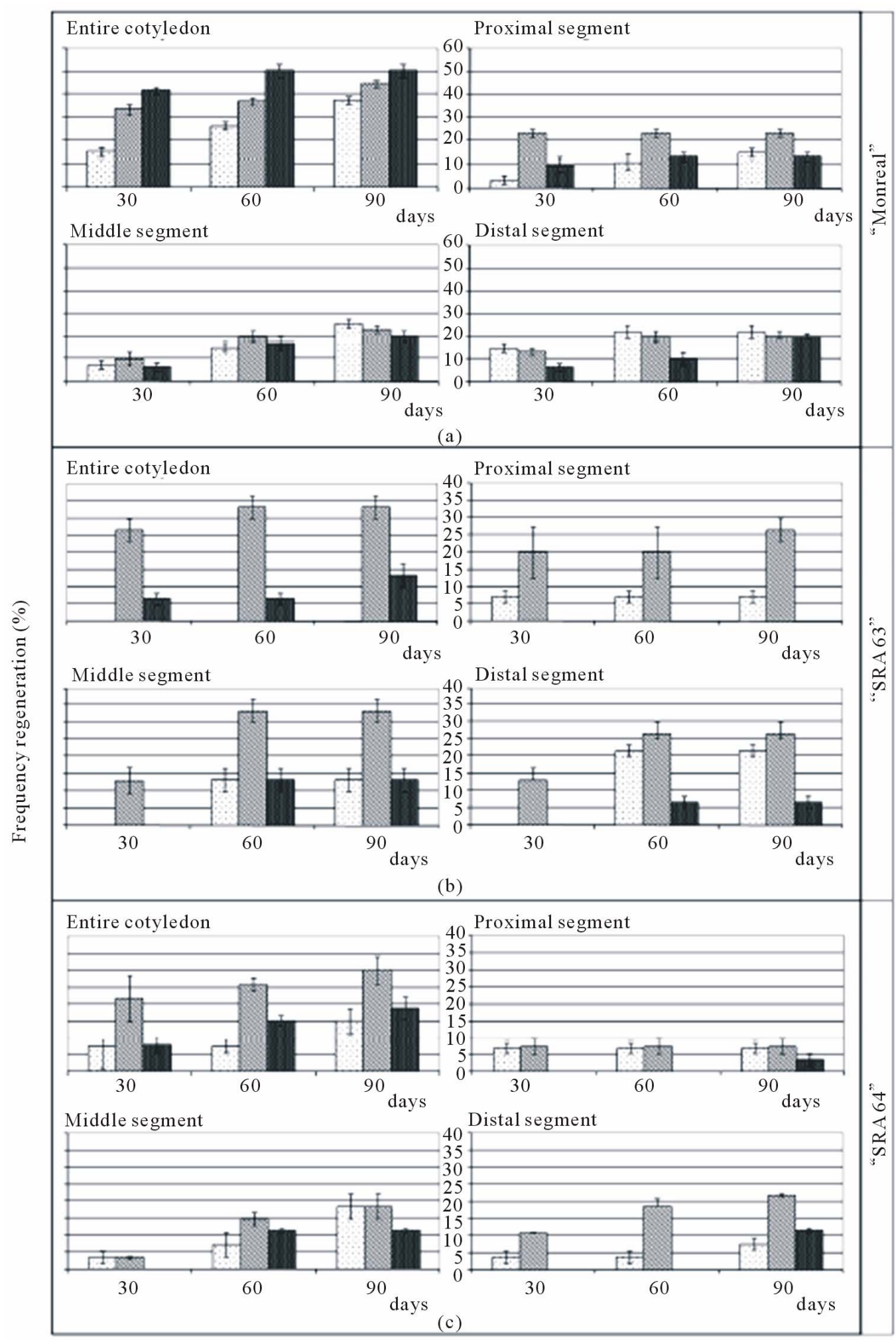

$\square 8.8 \mu \mathrm{M} \square 13.2 \mu \mathrm{M} \square 17.6 \mu \mathrm{M} \mathrm{BAP}$

Figure 2. Effect of BAP concentration on regeneration frequency (\%) from entire and transversely cut cotyledons (proximal, middle and distal segments) of Citrus clementina cultivars, "Monreal" (a) "SRA 63" (b) and "SRA 64" (c), at 30, 60 and 90 days of incubation. Vertical bars represent standard error of the means. 
Table 2. Influence of BAP concentration on number of buds/shoots differentiated per explant by direct organogenesis and the shoots' length $(\mathrm{mm})$ after 60 days of incubation in "Monreal", "SRA 63" and "SRA 64" Citrus clementina cultivars, in entire cotyledons (EC) and transversely cut cotyledons (CC), proximal (p), middle (m) and distal (d) segments. Mean \pm Standard error.

\begin{tabular}{|c|c|c|c|c|c|c|c|c|c|}
\hline \multirow{3}{*}{$\begin{array}{l}\text { Clementine } \\
\text { Cultivars }\end{array}$} & \multirow{3}{*}{$\begin{array}{l}\text { BAP } \\
(\mu \mathrm{M})\end{array}$} & \multicolumn{4}{|c|}{ Number of Buds/Shoots per Explant } & \multicolumn{4}{|c|}{ Length of Shoots } \\
\hline & & \multirow{2}{*}{$\mathrm{EC}$} & \multicolumn{3}{|c|}{$\mathrm{CC}$} & \multirow{2}{*}{$\mathrm{EC}$} & \multicolumn{3}{|c|}{$\mathrm{CC}$} \\
\hline & & & $\mathbf{p}$ & $\mathbf{m}$ & d & & $\mathbf{p}$ & $\mathbf{m}$ & d \\
\hline \multirow{3}{*}{ "Monreal" } & 8.8 & $3.14 \pm 0.79$ & $1.66 \pm 0.33$ & $2.75 \pm 1.10$ & $2.66 \pm 0.91$ & $3.82 \pm 0.88$ & $2.66 \pm 0.66$ & $2.50 \pm 1.19$ & $2.20 \pm 0.35$ \\
\hline & 13.2 & $4.27 \pm 1.18$ & $4.28 \pm 1.37$ & $2.50 \pm 0.26$ & $2.50 \pm 0.95$ & $5.20 \pm 1.16$ & $2.68 \pm 0.60$ & $2.38 \pm 0.57$ & $3.75 \pm 1.86$ \\
\hline & 17.6 & $3.6 \pm 0.68$ & $3.25 \pm 1.10$ & $2.40 \pm 0.60$ & $2 \pm 0.50$ & $5.98 \pm 1.24$ & $3.95 \pm 2.05$ & $1.60 \pm 0.40$ & $1 \pm 0$ \\
\hline \multirow{3}{*}{ “SRA 63" } & 8.8 & 0 & 7 & $3.50 \pm 1.50$ & $1 \pm 0$ & - & 2 & $1.25 \pm 0.25$ & $1.33 \pm 0.33$ \\
\hline & 13.2 & $4.2 \pm 1.11$ & $2.66 \pm 0.33$ & $3.20 \pm 0.91$ & $2.25 \pm 0.62$ & $6.44 \pm 2.34$ & $2 \pm 0$ & $2.20 \pm 0.84$ & $2.62 \pm 1.46$ \\
\hline & 17.6 & 4 & 0 & 1 & 1 & 7 & - & $2 \pm 0$ & 7 \\
\hline \multirow{3}{*}{ "SRA 64" } & 8.8 & $2.5 \pm 0.5$ & $3.50 \pm 1.50$ & $2.50 \pm 1.50$ & 1 & $2 \pm 0$ & $1 \pm 0$ & $1.90 \pm 0.1$ & 4 \\
\hline & 13.2 & $3.28 \pm 0.71$ & $3.50 \pm 1.50$ & $2.50 \pm 0.86$ & $2 \pm 0.77$ & $4.44 \pm 1.02$ & $1.25 \pm 0.25$ & $1.75 \pm 0.47$ & $3.3 \pm 0.7$ \\
\hline & 17.6 & $1.25 \pm 0.25$ & 0 & $1.66 \pm 0.66$ & 1 & $4.5 \pm 2.02$ & - & $1.33 \pm 0.33$ & 1 \\
\hline
\end{tabular}

three types of CC ones (Table $\mathbf{1}(\mathbf{C})$ ) and, beyond, the shoot elongation was not influenced significantly by the BAP concentration and the genotype. The transfer of longer shoots to fresh medium has more survival possibility than shorter ones (data not shown).

In previous and preliminary experiments cotyledons of seeds coming from fruits collected in November showed a similar pattern of morphogenic response with reference to the influence of BAP in comparison to seeds of December: 17.6 $\mu \mathrm{M}$ BAP for "Monreal" and 13.2 $\mu \mathrm{M}$ BAP for "SRA 63" and "SRA 64" were the best concentrations. Instead the regeneration frequency was higher (80\% RF in "Monreal", 75\% RF in "SRA 63" and 60\% in "SRA 64") and occurred better in CC than EC. This behavior may be explained by the fact that cells belonging to juvenile plant material have a higher regeneration competence and more rapid rates of proliferation in tissue cultures if compared to explants collected from mature tissue $[8,30]$. It should be noted that the regeneration frequency related to the explant physiological state depends on the species (species-specific), as indeed the mature cotyledons in soybean (Glycine max (L.) Merr.), for example, were observed to be more regenerative than immature ones [20]. The morphogenic inducting effect of wounds [31] may be more productive in younger tissues, making the $\mathrm{CC}$ explants more regenerative than EC.

In the present study, it was demonstrated that BAP is absolutely required to induce in vitro morphogenesis in clementine. In Citrus, the cytokinin 6-benzylaminopurine has been reported in a large number of protocols as promoting the formation of adventitious buds or shoots
[10,32-34]. Its use could reduce the risk of somaclonal variability in regenerants as opposed to diphenylurea derivates like N-(2-chloro-4-pyridyl)-N'-phenylurea that induces high levels of somaclonal variability [35]. The frequency of regeneration increased with the permanence in the medium supplemented with BAP, demonstrating that cells maintained their organogenic competence during the 90 incubation days.

Regeneration from cotyledon explants has been reported in several taxa [21-24,36,37] but it has been recorded in only a few species belonging to Citrus genus: adventive embryos formation in Citrus reticulata Blanco (Nagpur mandarin) and C. jambhiri Lush. (Rough lemon) [5], indirect somatic embryogenesis in C. reticulata "Local Sangtra" [38] and indirect shoot regeneration in $C$. grandis (L.) Osbeck (pummelo) [32,39].

\section{Conclusions}

Shoot regeneration in Citrus clementina can be obtained through direct organogenesis using cotyledons as explant and 6-benzylaminopurine growth regulator is essential to induce differentiation. The best BAP concentration for inducing regeneration has been determined as $17.6 \mu \mathrm{M}$ BAP for "Monreal" and 13.2 $\mu$ M BAP for "SRA 63" and "SRA 64" cultivars. The entire cotyledons were always more regenerative than transversely cut cotyledons for all the three cultivars, but a different morphogenic response was observed among the tested genotypes, showing "Monreal" having the highest organogenic potential.

This protocol may find application in Citrus genetic improvement and in studies concerning the achievement 
of new hybrids reducing the propagation time in respect to conventional methods. The obtained progeny, hybrid and heterogeneous, can be multiplied through direct adventitious shoot organogenesis, thus obtaining more identical individuals per seed who are more genetically stable in comparison to plants regenerated via callus, in which the presence of somaclonal variability is more probable. The plantlets, that can be transferred successfully in vivo in the greenhouse, may be monitored and evaluated for all new agronomic characteristics.

\section{Acknowledgements}

This work was supported by Regione Sicilia (Italy).

\section{REFERENCES}

[1] J. W. Cameron and H. B. Frost, "Genetics, Breeding and Nucellar Embryony,” In: W. Reuther, L. D. Batchelor and H. J. Webber, Eds., The Citrus Industry, University of California Press, Berkeley, Vol. 2, 1968, pp. 325-370.

[2] G. A. Moore, "Oranges and Lemon: Clues to the Taxonomy of Citrus from Molecular Markers," Trends in Genetics, Vol. 17, No. 9, September 2001, pp. 536-540. doi:10.1016/S0168-9525(01)02442-8

[3] E. Nicolosi, Z. N. Deng, A. Gentile, S. La Malfa, G. Continella and E. Tribulato, "Citrus Phylogeny and Genetic Origin of Important Species as Investigated by Molecular Markers," Theoretical and Applied Genetics, Vol. 100, No. 8, June 2000, pp. 1155-1166. doi:10.1007/s001220051419

[4] S. S. Raghuvanshi, "Cytological Studies in the Genus Citrus. IV. Evolution in the Genus Citrus," Cytologia, Vol. 27, 1962, pp. 172-188.

[5] R. N. Khawale and S. K. Singh, "In Vitro Adventitive Embryony in Citrus: A Technique for Citrus Germoplasm Exchange," Current Science, Vol. 88, No. 8, April 2005, pp. 1309-1311.

[6] S. Fiore, F. De Pasquale, F. Carimi and M. Sajeva, "Effect of 2,4-D and 4-CPPU on Somatic Embryogenesis from Stigma and Style Transverse Thin Cell Layers of Citrus," Plant Cell Tissue and Organ Culture, Vol. 68, No. 1, January 2002, pp. 57-63. doi:10.1023/A:1012944100210

[7] L. Navarro, J. M. Ortiz and J. Juarez, "Aberrant Citrus Plants Obtained by Somatic Embryogenesis of Nucelli Cultured in Vitro," HortScience, Vol. 20, No. 2, April 1985, pp. 214-215.

[8] F. Carimi and F. De Pasquale, "Micropropagation of Citrus," In: S. M. Jain and K. Ishii, Eds., Micropropagation of Woody Trees and Fruits, Kluwer Academic Publishers, Dordrecht, 2003, pp. 589-619.

[9] A. Carra, F. De Pasquale, A. Ricci and F. Carimi, "Diphenylurea Derivatives Induce Somatic Embryogenesis in Citrus," Plant Cell Tissue and Organ Culture, Vol. 87, No. 1, October 2006, pp. 41-48. doi:10.1007/s11240-006-9132-0
[10] M. G. C. Costa, V. S. Alves, E. R. G. Lani, P. R. Mosquim, C. R. Carvalho and W. C. Otoni, "Morphogenic Gradients of Adventitious Bud and Shoot Regeneration in Epicotyl Explants of Citrus," Scientia Horticulturae, Vol. 100, No. 1-4, March 2004, pp. 63-74. doi:10.1016/j.scienta.2003.08.007

[11] E. U. Khan, X. Z. Fu, J. Wang, Q. J. Fan, X. S. Huang, G. N. Zhang, J. Shi and J. H. Liu, "Regeneration and Characterization of Plants Derived from Leaf in Vitro Culture of Two Sweet Orange (Citrus sinensis (L.) Osbeck) Cultivars," Scientia Horticulturae, Vol. 120, No. 1, March 2009, pp. 70-76. doi:10.1016/j.scienta.2008.10.004

[12] R. Mukhtar, M. M. Khan, B. Fatima, M. Abbas and A. Shahid, "In Vitro Regeneration and Multiple Shoots Induction in Citrus Reticulata (Blanco)," International Journal of Agriculture Biology, Vol. 7, No. 3, 2005, pp. 414-416.

[13] M. Sajeva, A. Carra, F. De Pasquale and F. Carimi, "Somatic Embryogenesis and Plant Regeneration from Pistil Transverse Thin Cell Layers of Lemon (Citrus limon)," Plant Biosystems, Vol. 142, No. 2, July 2008, pp. 199-203. doi:10.1080/11263500802150258

[14] M. Kayim and N. K. Koc, "The Effect of Some Carbohydrates on Growth and Somatic Embryogenesis in Citrus Callus Culture," Scientia Horticulturae, Vol. 109, No. 1, June 2006, pp. 29-34. doi:10.1016/j.scienta.2006.01.040

[15] M. A. Germanà and B. Chiancone, "Gynogenetic Haploid of Citrus after in Vitro Pollination with Triploid Pollen Grains," Plant Cell Tissue and Organ Culture, Vol. 66, No. 1, July 2001, pp. 59-66. doi:10.1023/A:1010627310808

[16] B. Chiancone, A. Tassoni, N. Bagni and M. A. Germanà, "Effect of Polyamines on in Vitro Anther Culture of Citrus Clementina Hort. Ex Tan.," Plant Cell Tissue and Organ Culture, Vol. 87, No. 2, November 2006, pp. 145-153. doi:10.1007/s11240-006-9149-4

[17] M. A. Germanà, Y. Y. Wang, M. G. Barbagallo, G. IanNoliNo and F. G. Crescimanno, "Recovery of Haploid and Diploid Plantlets from Anther Culture of Citrus Clementina Hort. Ex Tan. and Citrus Reticula Blanco," Journal of Horticultural Science, Vol. 69, No. 3, 1994, pp. 473-480.

[18] M. A. Germanà and B. Chiancone, "Improvement of Citrus Clementina Hort. Ex Tan. Microspore-Derived Embryoid Induction and Regeneration," Plant Cell Reports, Vol. 22, No. 3, October 2003, pp. 181-187. doi:10.1007/s00299-003-0669-7

[19] D. W. Burger and W. P. Hackett, "The Isolation, Culture and Division of Protoplasts from Citrus Cotyledons," Physiologia Plantarum, Vol. 56, No. 3, November 1982, pp. 324-328. doi:10.1111/j.1399-3054.1982.tb00346.x

[20] G. Franklin, L. Carpenter, E. Davis, C. S. Reddy, D. Al-Abed, W. A. Alaiwi, M. Parani, B. Smith, S. L. Goldman and R. V. Sairam, "Factors Influencing Regeneration of Soybean from Mature and Immature Cotyledons," Plant Growth Regulation, Vol. 43, No. 1, May 2004, pp. 73-79. doi:10.1023/B:GROW.0000038359.86756.18 
[21] K. Sujatha, B. M. Panda and S. Hazra, "De Novo Organogenesis and Plant Regeneration in Pongamia Pinnata, Oil Producing Tree Legume," Trees, Vol. 22, No. 5, October 2008, pp. 711-716.

[22] R. V. Sairam, G. Franklin, R. Hassel, B. Smith, K. Meeker, N. Kashikar, M. Parani, D. Al-Abed, S. Ismail, K. Berry and S. L. Goldman, "A Study on the Effect of Genotypes, Plant Growth Regulators and Sugars in Promoting Plant Regeneration via Organogenesis from Soybean Cotyledonary Nodal Callus," Plant Cell Tissue and Organ Culture, Vol. 75, No. 1, October 2003, pp. 79-85. doi:10.1023/A:1024649122748

[23] A. K. Singh, S. Chand, S. Pattnaik and P. K. Chand, "Adventitious Shoot Organogenesis and Plant Regeneration from Cotyledons of Dalbergia Sissoo Roxb., a Timber Yielding Tree Legume," Plant Cell Tissue and Organ Culture, Vol. 68, No. 2, February 2002, pp. 203-209. doi:10.1023/A:1013870803937

[24] A. Joshi and S. L. Kothari, "High Copper Levels in the Medium Improves Shoot Bud Differentiation and Elongation from the Cultured Cotyledons of Capsicum Annum L.," Plant Cell Tissue and Organ Culture, Vol. 88, No. 2, February 2007, pp. 127-133. doi:10.1007/s11240-006-9171-6

[25] R. Chaturvedi and S. P. Bhatnagar, "High-Frequency Shoot Regeneration from Cotyledon Explants of Watermelon cv. Sugar Baby," In Vitro Cellular \& Developmental Biology-Plant, Vol. 37, No. 2, March 2001, pp. 255-258. oi:10.1007/s11627-001-0045-7

[26] T. Murashige and F. Skoog, "A Revised Medium for Rapid Growth and Bioasseys with Tobacco Tissue Culture," Physiologia Plantarum, Vol. 15, No. 3, July 1962, pp. 473-497. doi:10.1111/j.1399-3054.1962.tb08052.x

[27] P. McCullagh and J. A. Nelder, "Generalized Linear Models," Chapman and Hall, London, 1989.

[28] H. Akaike, "A New Look at the Statistical Model Identification," IEEE Transactions on Automatic Control, Vol. 19, No. 6, December 1974, pp. 716-723. doi:10.1109/TAC.1974.1100705

[29] R Development Core Team, "R: A Language and Environment for Statistical Computing," R Foundation for Statistical Computing, Vienna, 2005. http://www.R-project.org.

[30] P. J. Ainsley, F. A. Hammerschlag, T. Bertozzi, G. G. Collins and M. Sedley, "Regeneration of Almond from Immature Seed Cotyledons," Plant Cell Tissue and Organ Culture, Vol. 67, No. 3, December 2001, pp. 221-226.

\section{doi:10.1023/A:1012700714085}

[31] S. Ogita, E. C. Yeung, H. Sasamoto, "Histological Analysis in Shoot Organogenesis from Hypocotyl Explants of Kandelia Candel (Rhizophoraceae)," Journal of Plant Research, Vol. 117, No. 6, December 2004, pp. 457-464. doi:10.1007/s10265-004-0180-4

[32] F. Begum, M. N. Amin, S. Islam, M. A. K. Azad and M. M. Rehman, "In Vitro Plant Regeneration from Cotyledon-Derived Callus of Three Varieties Pummelo (Citrus Grandis (L.) Osb.)," Journal of Biological Science, Vol. 3, No. 8, November 2003, pp. 751-759. doi:10.3923/jbs.2003.751.759

[33] Y. Bordon, J. L. Guardiola and A. Garcia-Luis, "Genotype Affects the Morphogenic Response in Vitro of Epicotyl Segments of Citrus Rootstocks," Annals of Botany, Vol. 86, No. 1, July 2000, pp. 159-166. doi:10.1006/anbo.2000.1177

[34] B. Chakravarty and B. C. Goswami, "Plantlet Regeneration from Long-Term Callus Cultures of Citrus Acida Roxb. and Uniformity of Regenerated Plants," Scientia Horticulturae, Vol. 82, No. 1-2, December 1999, pp. 159-169. doi:10.1016/S0304-4238(99)00047-3

[35] M. Siragusa, A. Carra, L. Salvia, A. M. Puglia, F. De Pasquale and F. Carimi, "Genetic Instability in Calamondin (Citrus Madurensis Lour.) Plants Derived from Somatic Embryogenesis Induced by Diphenylurea Derivates," Plant Cell Reports, Vol. 26, No. 8, August 2007, pp. 1289-1296. doi:10.1007/s00299-007-0326-7

[36] N. Du and P. M. Pijut, "Regeneration of Plants from Fraxinus Pennsylvanica Hypocotyls and Cotyledons," Scientia Horticulturae, Vol. 118, No. 1, September 2008, pp. 74-79. doi:10.1016/j.scienta.2008.05.014

[37] H. Saafi and D. Borthakur, "In Vitro Plantlet Regeneration from Cotyledons of the Tree-Legume Leucaena Leucocephala," Plant Growth Regulation, Vol. 38, No. 3, November 2002, pp. 279-285.

[38] M. I. S. Gill, Z. Singh, B. S. Dhillon and S. S. Gosal, "Somatic Embryogenesis and Plantlet Regeneration in Mandarin (Citrus Reticula Blanco)," Scientia Horticulturae, Vol. 63, No. 3-4, September 1995, pp. 167-174. doi:10.1016/0304-4238(95)00812-8

[39] C. J. Goh, G. E. Sim, C. L. Morales and C. S. Loh, "Plantlet Regeneration through Different Morphogenic Pathways in Pommelo Tissue Culture," Plant Cell Tissue and Organ Culture, Vol. 43, No. 3, December 1995, pp. 301-303. 